\title{
A category approach to predicting the hemolytic effects of ethylene glycol alkyl ethers in repeated-dose toxicity
}

\author{
Takashi Yamada1', Yushiro Tanaka1', HuiQi Zhang'1, Ryuichi Hasegawa', Yuki Sakuratani1, \\ Ovanes Mekenyan², Yasushi Yamazoe ${ }^{3}$, Jun Yamada' and Makoto Hayashi ${ }^{4}$

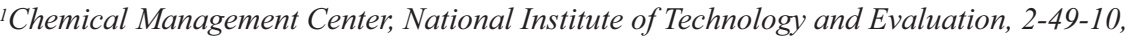 \\ Nishihara, Shibuya-ku, Tokyo 151-0066, Japan \\ ${ }^{2}$ Laboratory of Mathematical Chemistry, University "Prof. Assen Zlatarov" Bourgas, \\ 1 "Yakimov" Str. 8010 Bourgas, Bulgaria \\ ${ }^{3}$ Graduate School of Pharmaceutical Sciences, Tohoku University, Aoba-ku, Sendai, 980-8578, Japan \\ ${ }^{4}$ Biosafety Research Center, Foods, Drugs and Pesticides, 582-2, Shioshinden, Iwata, Shizuoka 437-1213 Japan
}

(Received December 22, 2011; Accepted February 7, 2012)

\begin{abstract}
Categorizing chemicals is an approach with the potential to reduce animal testing for hazard assessment of chemicals. In this study we investigated the category approach for testing the hemolytic effects of ethylene glycol alkyl ethers (EGAEs) for repeated-dose toxicity (RDT). Using mechanistic information on the hemolytic effects of ethylene glycol butyl ether, a toxicologically meaningful category was built on the basis of similarity of metabolism, mode of action and the hemolytic effects of several EGAEs and related chemicals. The developed category was then evaluated for analogs from a different data source. Given all structural information on category chemicals, the category can be finally defined as EGAEs (alkyl chain carbon number: 1-4) and their acetates. Current RDT test data suggest that EGAEs with 3 and 4 alkyl carbons primarily cause hemolytic effects, while EGAEs with 1 and 2 alkyl carbon(s) show toxicity to the testis before demonstrating any hemolytic effects. Hence, the category approach appears to be applicable to hemolytic effects of EGAEs with 3 and 4 alkyl carbons and their acetates to estimate the no observable adverse effect level (NOAEL) for RDT. It consists of three steps: structure-based primary screening of untested chemicals, categorization of compounds that form hemolytic alkoxyacetic acids by predicting how they are metabolized, and finally estimation of hemolytic levels by employing read-across. Our results clearly demonstrate the usefulness of the category approach for predicting the hemolytic effects of untested EGAEs and their acetates in RDT.
\end{abstract}

Key words: Category approach, Repeated-dose toxicity, Ethylene glycol alkyl ether, Hemolytic anemia

\section{INTRODUCTION}

In regulatory toxicology, repeated-dose toxicity $(\mathrm{RDT})$ is an essential item of information for hazard evaluation of industrial chemicals. The number of chemicals for which RDT has been tested, however, is limited, since toxicity testing is costly and time-consuming. However, chemical regulation policies are increasingly requiring that RDT data be made available for marketed but untested chemicals. The category approach therefore has potential as a useful method of hazard evaluation of hitherto untested chemicals. Using this approach, chemicals whose toxicological properties are likely to be similar, or which show a regular pattern of behavior as a result of structural similarity, are grouped into a chemical category. If an untested chemical falls into this category, its toxicity is estimated using data for tested analogs in this category. This is termed "data gap filling." The category approach is increasingly finding acceptance for several regulatory endpoints (OECD, 2007; Schaafsma et al., 2009; van Leeuwen et al., 2009). However, it is less commonly applied to RDT, since chemicals that are similar as to molecular structure often have dissimilar toxic effects. Hence, chemicals with a common toxicological mechanism need to be grouped into categories to increase reliability, causality and confidence in toxicity prediction. Plausible connections between chemicals, key events and adverse outcome are now proposed as adverse outcome

Correspondence: Takashi Yamada (E-mail: yamada-takashi@nite.go.jp) 
pathway (AOP) (Ankley et al., 2010; Schultz, 2010); and AOP is increasingly regarded as valuable for forming toxicologically meaningful categories (OECD, 2011). Several attempts have recently been made to form categories (Fabjan et al., 2006; Sakuratani et al., 2008) and for data gap filling by read-across (Wu et al., 2010; Blackburn et al., 2011) for complicated toxicity endpoints.

Some ethylene glycol alkyl ethers (EGAEs) are highproduction-volume chemicals with a wide range of industrial uses, such as in paints, varnishes, resins, engine fuels, and hydraulic fluids; and in many household products, including floor polishes, and glass, leather, and upholstery cleaners. Since the 1980s, concerns over potential human exposure, as well as initial reports suggesting potential toxicity, resulted in extensive research efforts to characterize the toxic effects of EGAEs (NIOSH, 1990; NIOSH, 1991). EGAEs are reported to induce various toxicities in laboratory animals, including hematotoxicity as well as reproductive and developmental toxicities. These are generally dependent on dose and alkyl carbon chain length (Johanson, 2000; Johnson, 2002; OECD, 2004). Ethylene glycol butyl ether (EGBE), which has a straight alkyl chain of 4 carbons, is one of the major marketed EGAEs. Repeated administration of EGBE primarily causes hemolytic anemia, but does not cause reproductive or developmental toxicities (NTP, 1993; CICAD, 2005). The hemolytic mechanism has been studied extensively (Ghanayem et al., 1987; Ghanayem, 1989; Udden, 2002). Some EGAEs appear to be similar to EGBE in terms of hemolytic effects and mechanism of action. However, the hemolytic effects have not been fully evaluated for all existing EGAEs and related chemicals. Because of the potential exposure to various EGMEs and related chemicals through consumer products, filling lack of the toxicity data is desirable.

In this study, category approach was applied to predict the hemolytic effects of EGAEs and related chemicals. A toxicologically meaningful category was built on the basis of similarity of metabolism, mode of action and hemolytic effects of several EGAEs and related chemicals. The developed category was then evaluated with the category candidates from a different data source. Finally, as-yet untested EGAEs and related chemicals were categorized and the hemolytic effects were predicted based on the toxicity data of suitable analog(s). Results of category validation support the reliability of prediction of hemolytic effects of untested EGAEs and related chemicals.

\section{MATERIALS AND METHODS}

\section{Data set}

One criterion for selection for EGAEs was the carbon number of the alkyl chain, since the aim was to determine the boundary of the alkyl chain of EGAEs for hemolytic effects. The EGAE-related chemicals were chosen according to similarities in chemical structure, physicochemical properties, chemical reactivity and metabolism. To develop a category, six chemicals were chosen from our RDT database (Hayashi and Sakuratani, 2011). This database consists of a data set of 500 (mainly industrial) chemicals, most of which are derived from RDT studies conducted under Good Laboratory Practice as defined in the Japanese Chemical Substances Control Law (http:// dra4.nihs.go.jp/mhlw_data/jsp/SearchPageENG.jsp) and the National Toxicology Program (NTP) of the National Institutes of Health in the USA (http://ntp.niehs.nih.gov/). The database will be published in 2012 and is provisionally termed the RDT DB in this study. For evaluating a category, seven chemicals were selected from RepDose DB, a database on RDT studies of commercial chemicals developed by Fraunhofer Institute of Toxicology and Experimental Medicine, Germany, (Bitsch et al., 2006). Chemicals and their abbreviations, and the data source of the RDT test data are depicted in Table 1.

\section{Development of AOP and category}

Literatures on RDT, metabolism and various in vitro and in vivo toxicological studies were gathered for EGAEs. Using the evidence of nearly 30 years of studies, an AOP was built for the hemolytic effects of EGBE, the most extensively studied EGAE, taking into account strength, consistency, and specificity of association of initiating key events and adverse outcomes. To identify hemolytic chemicals, significant decrease in red blood cell (RBC) counts, hemoglobin concentration and hematocrit were utilized as indicators of primary hemolytic effects, and a significant increase in reticulocyte counts and splenic hemosiderin pigmentation were confirmed as secondary hemolytic effects. Hemolytic levels were evaluated as the lowest observed adverse effect level (LOAEL) and the lower confidence limit on the benchmark dose associated with a $10 \%$ response (Benchmark Dose Lower Bound $10 \%$ : $B M D L_{10}$ ) for RBC decrease. Using US EPA-provided Benchmark Dose Software (Version 2.1.2), $\mathrm{BMDL}_{10}$ for $\mathrm{RBC}$ decrease $\left(\mathrm{BMDL}_{10 \mathrm{RBC}} \downarrow\right)$ was estimated with a $10 \%$ reduction as relative deviation of BMR type at the $95 \%$ confidence level. Dose, animal number, RBC counts and standard deviation were input to a Continuous Model. For selection of the model, the lowest data was used by visual confirmation of the goodness-of-fit using graphical displays. If hematology data were available for both males and females, the data indicating the more severe hemolytic effects were utilized. 
Category approach for repeated-dose toxicity

Table 1. Chemicals, their abbreviations and the RDT test data source in this study

\begin{tabular}{lll}
\hline Abbreviation & Chemical name & Data source of RDT test (database) \\
\hline EGME & Ethylene glycol methyl ether & NTP, 1993 (RDT DB and RepDose DB) \\
EGEE & Ethylene glycol ethyl ether & NTP, 1993 (RDT DB and RepDose DB) \\
EGiPE & Ethylene glycol isopropyl ether & MHLW, 2002 (RDT DB and RepDose DB) \\
EGiPEA & Ethylene glycol isopropyl ether acetate & Not available \\
EGPE & Ethylene glycol propyl ether & Katz et al., 1984 (RepDose DB) \\
EGPEA & Ethylene glycol propyl ether acetate & Katz et al., 1984 (RepDose DB) \\
EGtBE & Ethylene glycol tert-butyl ether & MHLW, 2001 (RDT DB) \\
EGiBE & Ethylene glycol isobutyl ether & Not available \\
EGBE & Ethylene glycol butyl ether & NTP, 1993 (RDT DB and RepDose DB) \\
EGBEA & Ethylene glycol butyl ether acetate & Not available \\
EGHE & Ethylene glycol hexyl ether & Klonne et al., 1987 (RepDose DB) \\
DGPE & Diethylene glycol propyl ether & Not available \\
DGBE & Diethylene glycol butyl ether & Johnson et al., 2005 (RepDose DB) \\
PGMEA & Propylene glycol methyl ether acetate & MHLW, 1998 (RDT DB) \\
PGME & Propylene glycol methyl ether & Landry et al., 1983 (RepDose DB) \\
PGPE & Propylene glycol propyl ether & ECETOC, 1995 (RepDose DB) \\
PGBE & Propylene glycol butyl ether & ECETOC, 1995 (RepDose DB)
\end{tabular}

A data matrix was constructed and carefully evaluated in terms of category candidates, formation of alkoxyacetic acid and swelling of RBC as key events, and significant decrease in RBC counts as an indicator of hemolytic effects, to develop a toxicologically meaningful category. Finally, category definition was described on the basis of chemical structure and metabolism of the category chemicals.

\section{Prediction of the hemolytic effects of category candidates}

The chemical inventory of the Ministry of International Trade and Industry (MITI), Japan was first screened to obtain chemicals containing a EGAE substructure with alkyl chains of 3 and 4 carbons using the OECD QSAR Toolbox Ver. 2.1 (http://www.oecd.org/document/54/0,37 46,en_2649_34379_42923638_1_1_1_1,00.html), a freely available software application that incorporates information on chemical and various toxicity data and has a function for grouping chemicals. After dataset chemicals had been removed, the remaining EGAE, acetate ester of EGAE and diethylene glycol alkyl ether were chosen as untested category candidates. The name of the remaining four chemicals is listed in Table 1. Their metabolism was predicted based on documented metabolism information on analog chemicals for categorization. Presumed hemo- lytic levels were estimated by read-across with $\mathrm{BMDL}_{10}$ $\mathrm{RBC} \downarrow$ (if available) or $\mathrm{LOAEL}_{\mathrm{RBC} \downarrow}$ of suitable tested analog(s).

\section{RESULTS}

\section{Building an AOP for the hemolytic effects of EGBE}

An AOP represents existing knowledge of the linkage between a chemical, the molecular initiating event and the adverse outcome at individual (or population) level (Ankley et al., 2010). Since more studies on EGAEinduced hemolysis have been performed with EGBE, the AOP for EGBE-induced hemolytic effects was built by taking into account the strength, consistency, and specificity of the association with a series of sets of experimental evidence, as shown in Fig. 1.

There is strong evidence to support the proposed AOP. Repeated inhaled and oral administration of EGBE caused acute and subacute hemolytic effects (NTP, 1993, 2000; OECD, 2004). Pretreatment of rats with pyrazole, an alcohol dehydrogenase inhibitor, or cyanamide, an aldehyde dehydrogenase inhibitor, suppressed butoxyacetic acid formation and EGBE-induced hemolysis (Ghanayem et al., 1987). Pyrazole inhibition of EGBE metabolism to butoxyacetic acid was accompanied by an increase in 


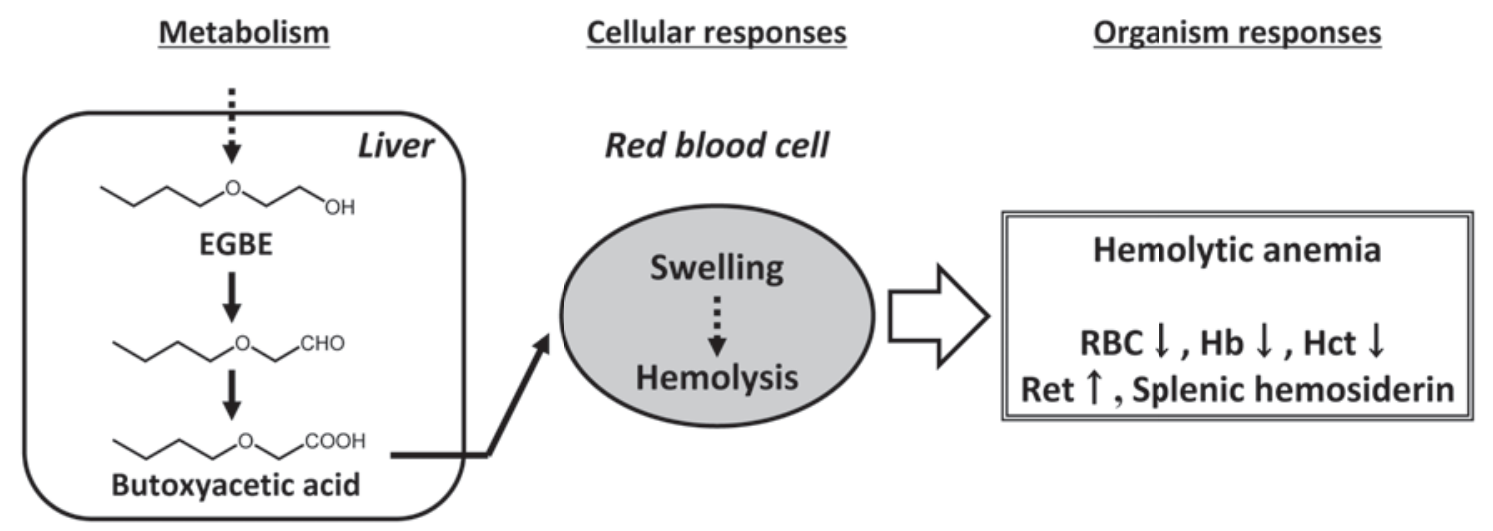

Fig. 1. AOP of EGBE-induced hemolytic anemia in rats. EGBE is readily absorbed following inhalation, oral and dermal exposure. EGBE is primarily oxidized by alcohol dehydrogenase to yield butoxyaldehyde, predominantly in the liver. Further conversion of the aldehyde by aldehyde dehydrogenase produces butoxyacetic acid. Unlike EGBE, butoxyacetic acid is not rapidly cleared from the blood, and interacts with RBCs. Butoxyacetic acid apparently acts as a possible toxicant that induces swelling of RBCs and subsequent hemolysis. The adverse outcome is identified by hematology data in RDT tests including decrease in RBC count $(\mathrm{RBC} \downarrow)$, decrease in hemoglobin concentration $(\mathrm{Hb} \downarrow)$ and decrease in hematocrit (Hct $\downarrow)$, as well as increased reticulocyte count (Ret $\uparrow$ ) and hemosiderin pigmentation in the spleen.

EGBE metabolism to the glucuronide and sulfate metabolites in urine (Ghanayem et al., 1987). There was a correlation between the amount of butoxyacetic acid in the urine and EGBE-induced hematotoxicity (Ghanayem et al., 1987). Moreover, equimolar amounts of butoxyacetic acid administration induced hemolysis at similar levels of EGBE (Ghanayem et al., 1987). Incubation of rat RBCs with butoxyacetic acid induced swelling and subsequent leakage of hemoglobin in a dose-dependent manner (Ghanayem et al., 1989). The molecular initiating event elicited by butoxyacetic acid is unknown. One possible explanation is that hemolytic effects might start with a specific interaction between the alkoxyacetic acid moiety and an unidentified component of the RBC membrane, causing disruption of the osmotic balance (Ghanayem, 1989). It has also been proposed that butoxyacetic acid causes colloid osmotic swelling of RBCs (Udden and Patton, 2005). Morphological changes in RBCs characterized as having a cup-shaped form, induced by butoxyacetic acid in vitro, were similar to those induced by EGBE administration in vivo (Udden, 2000). The altered cells may be destroyed by macrophages in the spleen or liver (Udden and Patton, 2005). None of the minor metabolites have been shown to be toxic. AOP identifies a measurable key event linked to an adverse outcome for developing a category. In this AOP, metabolic formation of hemolytic alkoxyacetic acids is critical information associated with hemolysis to form an EGAE category for hemolytic effects.

\section{Development of EGAE category for hemolytic effects}

To develop a category for EGAEs, the following six chemicals were selected from the RDT DB, based on variations in the alkyl chain: ethylene glycol methyl ether (EGME), ethylene glycol ethyl ether (EGEE), ethylene glycol isopropyl ether (EGiPE), ethylene glycol tert-butyl ether (EGtBE), ethylene glycol butyl ether (EGBE) and propylene glycol methyl ether acetate (PGMEA). Table 2 shows a matrix that compares metabolism, RBC swelling activity and hemolysis in rats for each of these chemicals. EGME, EGEE, EGiPE and EGBE were chiefly metabolized to the corresponding alkoxyacetic acids (Miller et al., 1984a; Sumner et al., 1995; Cheever et al., 1984; Hutson and Pickering, 1971; Ghanayem et al., 1987; Sabourin et al., 1992). EGME showed weak hemolytic activity in RDT (NTP, 1993), which was supported by evidence of slight swelling activity of rat RBCs when exposed to methoxyacetic acid in vitro and no significant mean corpuscular volume (MCV) increase in vivo (Ghanayem et al., 1989; NTP, 1993). Ethoxyacetic and butoxyacetic acids apparently showed swelling of rat RBCs and hemolysis in vitro (Ghanayem et al., 1989). Moreover, repeated administration of EGEE, EGiPE, EGtBE or EGBE to rats induced a significant increase in MCV and hemolysis (NTP, 1993; MHLW, 2001, 2002). Propylene glycol methyl ether acetate (PGMEA) was readily hydrolyzed to $\mathrm{PGME}$, which underwent $O$-demethylation and conjugation to form propylene gly- 
Category approach for repeated-dose toxicity

Table 2. A toxicity data matrix for EGAEs and related chemicals from the RDT DB for forming a category

$\begin{array}{lccc}\text { Chemical structure } & \text { Alkoxyacetic acid } & \text { fwelling of RBC } & \text { Hemolytic effects and levels } \\ \text { Name } & \text { formation } & \text { (in vitro) })^{* 1} & \text { Strain of rat, duration, route } \\ \text { CAS No. } & \text { (in vivo) } & \text { (in vivo) })^{* 2} & \text { Dose }\end{array}$

\begin{tabular}{|c|c|c|c|}
\hline $\begin{array}{c}\text { EGME } \\
109-86-4\end{array}$ & $\begin{array}{c}+ \\
(\text { in vivo })\end{array}$ & $\begin{array}{c}+ \\
(\text { in vitro })\end{array}$ & $\begin{array}{c}\text { LOAEL }_{\mathrm{RBC} \downarrow} ; 4500 \mathrm{ppm}(9.4 \mathrm{mmol} / \mathrm{kg} / \mathrm{d}), \\
\mathrm{BMDL}_{10 \mathrm{RBC} \downarrow} ; 5.50 \mathrm{mmol} / \mathrm{kg} / \mathrm{d} \\
\mathrm{F}^{2} 44 \text { rat, } 13-\mathrm{w}, \text { drinking water } \\
750,1500,3000,4500 \mathrm{ppm}\end{array}$ \\
\hline $\begin{array}{c}\text { EGEE } \\
110-80-5\end{array}$ & $\begin{array}{c}+ \\
(\text { in vitro }) \\
(\text { in vivo })\end{array}$ & $\begin{array}{c}+ \\
(\text { in vitro }) \\
(\text { in vivo })\end{array}$ & $\begin{array}{c}\text { LOAEL }_{\mathrm{RBC} \downarrow} ; 5000 \mathrm{ppm}(4.4 \mathrm{mmol} / \mathrm{kg} / \mathrm{d}), \\
\mathrm{BMDL}_{10 \mathrm{RBC} \downarrow} ; 4.31 \mathrm{mmol} / \mathrm{kg} / \mathrm{d} \\
\mathrm{F}_{4} 44 \mathrm{rat}, 13-\mathrm{w}, \text { drinking water } \\
1250,2500,5000,10000 \mathrm{ppm}\end{array}$ \\
\hline $\begin{array}{c}\text { EGiPE } \\
109-59-1\end{array}$ & $\begin{array}{c}+ \\
(\text { in vivo })\end{array}$ & $\begin{array}{c}+ \\
(\text { in vivo })\end{array}$ & $\begin{array}{c}\mathrm{LOAEL}_{\mathrm{RBC} \downarrow} ; 125 \mathrm{mg} / \mathrm{kg} / \mathrm{d}(1.2 \mathrm{mmol} / \mathrm{kg} / \mathrm{d}) \\
\mathrm{BMDL}_{10 \mathrm{RBC} \downarrow} ; 0.74 \mathrm{mmol} / \mathrm{kg} / \mathrm{d} \\
\mathrm{SD} \mathrm{rat}, 28-\mathrm{d}, \text { gavage } \\
30,125,500 \mathrm{mg} / \mathrm{kg} / \mathrm{d}\end{array}$ \\
\hline $\begin{array}{c}\text { EGtBE } \\
7580-85-0\end{array}$ & $\begin{array}{c}\text { No data } \\
\text { found }\end{array}$ & $\begin{array}{c}+ \\
(\text { in vivo })\end{array}$ & $\begin{array}{c}\text { LOAEL }_{\mathrm{RBC} \downarrow} ; 100 \mathrm{mg} / \mathrm{kg} / \mathrm{d}(0.85 \mathrm{mmol} / \mathrm{kg} / \mathrm{d}) \\
\text { BMDL }_{10 \mathrm{RBC} \downarrow} ; 0.33 \mathrm{mmol} / \mathrm{kg} / \mathrm{d} \\
\mathrm{SD} \text { rat, } 42-\mathrm{d}, \text { gavage } \\
4,20,100 \mathrm{mg} / \mathrm{kg} / \mathrm{d}\end{array}$ \\
\hline $\begin{array}{c}\text { EGBE } \\
111-76-2\end{array}$ & $\begin{array}{c}+ \\
(\text { in vitro }) \\
(\text { in vivo })\end{array}$ & $\begin{array}{c}+ \\
(\text { in vitro }) \\
(\text { in vivo })\end{array}$ & $\begin{array}{c}\text { LOAEL }_{\text {RBC } \downarrow} ; 750 \mathrm{ppm}(0.69 \mathrm{mmol} / \mathrm{kg} / \mathrm{d}) \\
\text { BMDL }_{10 \mathrm{RBC} \downarrow}: 0.86 \mathrm{mmol} / \mathrm{kg} / \mathrm{d} \\
\text { F344 rat, } 13-\mathrm{w}, \text { drinking water } \\
750,1500,3000,4500,6000 \mathrm{ppm}\end{array}$ \\
\hline $\begin{array}{l}\text { PGMEA } \\
108-65-6\end{array}$ & $\begin{array}{c}- \\
(\text { in vivo })\end{array}$ & $\begin{array}{c}- \\
(\text { in vivo) }\end{array}$ & $\begin{array}{c}\text { No effects on RBC; } 1000 \mathrm{mg} / \mathrm{kg} / \mathrm{d}(7.6 \mathrm{mmol} / \mathrm{kg} / \mathrm{d}) \\
\text { SD rat, } 44-\mathrm{d} \text {, gavage, } \\
30,100,300,1000 \mathrm{mg} / \mathrm{kg} / \mathrm{d}\end{array}$ \\
\hline
\end{tabular}

col and PGME-glucuronide and -sulfate, respective1y. No methoxyacetic acid was detected in rats (Miller et al., 1984b). Repeated administration of PGMEA caused no hemolytic effects or any other pathological changes (MHLW, 1998).

Taken together, EGME, EGEE, EGiPE, EGtBE and EGBE appear to be similar as to metabolism, mode of action and hemolytic effects. Hence, they can be included in the EGAE category for hemolytic effects. PGMEA is not included in this category due to absence of metabolic formation of methoxyacetic acid and lack of hemolytic effects. However, the metabolic features of this chemical suggest that metabolic convergence to category chemicals needs to be taken into account when forming a category. A previous study demonstrated the rapid hydrolysis of PGMEA in vivo to PGME and showed that, once hydrolyzed, the kinetics of PGME derived from PGMEA are identical to those of PGME (Domoradzki et al., 2003). It is thus reasonable to conclude that chemicals such as acetate esters of EGAE are converted to hemolytic EGAE. Examining the chemical structure of category chemicals and the toxicokinetic features of other related chemicals allows the chemical space of the category to be described. The category we propose is the group of EGAE (alkyl 
chain carbon number: 1-4) or chemicals with the EGAE substructure, which are metabolized chiefly to the corresponding alkoxyacetic acid. These category members produce hemolytic anemia by acting via the AOP of EGBE.

\section{Evaluation of a proposed category for analogs from a different data source}

To evaluate the proposed category, EGAEs and related chemicals were obtained from RepDose DB, a different data source. All EGAEs were initially selected; and acetate ester of EGAE, diethylene glycol alkyl ether and propylene glycol alkyl ether were then selected based on similarities in chemical structure, physicochemical properties, and chemical reactivity. Chemicals already present in the RDT DB, and chemicals whose hematology data in rats are not available in RepDose DB, were then eliminated. The remaining seven chemicals are listed in Table 3.

The first chemical, ethylene glycol propyl ether (EGPE) has a straight alkyl chain with 3 carbons. This chemical appears to be within the boundary of the proposed category. No documented metabolism information was found, but it is reasonable to presume that EGPE is metabolized to propoxyacetic acid by analogy with the metabolism of EGEE and EGBE (Fig. 2A). This suggests that EGPE is a member of this category and thus causes hemolytic effects. The presumed NOAEL for hemolysis was roughly estimated by averaging the $\mathrm{BMDL}_{10}$ ${ }_{\mathrm{RBC}} \downarrow$ of EGEE, EGiPE and EGBE (interpolation) as $2.0 \mathrm{mmol} / \mathrm{kg} / \mathrm{d}$. In the RDT study in rats receiving EGPE for 6 weeks by gavage, dose-related hemolytic anemia was observed at $1.9 \mathrm{mmol} / \mathrm{kg} / \mathrm{d}$ or more (Katz et al., 1984) and the $\mathrm{BMDL}_{10 \mathrm{RBC} \downarrow}$ was estimated to be $2.3 \mathrm{mmol} / \mathrm{kg} / \mathrm{d}$ with default standard deviation (4.5\%).

The second chemical, ethylene glycol propyl ether acetate (EGPEA) contains an EGPE substructure linked with an acetyl group via an ester bond. There is no documented metabolism data found for this chemical. The structural analogs, ethylene glycol ethyl ether acetate (EGEEA) and diethylene glycol butyl ether acetate (DGBEA), were reported to be rapidly hydrolyzed to form EGEE and DGBE, respectively, as major metabolites (Stott and McKenna, 1985; Gargas et al., 2000; Deisinger and Guest, 1989). Hence it is reasonable to assume that EGPEA is readily hydrolyzed to EGPE (Fig. 2B) and exerts its hemolytic effects with similar severity to EGPE. Repeated gavage exposure to EGPEA for 6 weeks in rats primarily produced dose-dependent hemolytic changes at $7.5 \mathrm{mmol} / \mathrm{kg} / \mathrm{d}$ and above (Katz et al., 1984). From this dose-response relationship, $\mathrm{BMDL}_{10 \mathrm{RBC} \downarrow}$ of EGPEA was calculated to be $3.0 \mathrm{mmol} / \mathrm{kg} / \mathrm{d}$ (using a default standard deviation of $4.5 \%$ ), while the $\mathrm{BMDL}_{10 \mathrm{RBC}} \downarrow$ of EGPE is already known above to be $2.3 \mathrm{mmol} / \mathrm{kg} / \mathrm{d}$. These similar responses may indicate that the same ultimate substance produces hemolysis in spite of slight differences derived from the additional hydrolysis step.

EGHE was shown to be oxidized to hexoxyaldehyde in rat liver homogenate (Aasmore et al., 1998). The aldehyde metabolite is thought to be converted to hexoxyacetic acid (Fig. 2C), in line with the documented metabolism of EGBE to butoxyacetic acid and DGBE to butoxyethoxyacetic acid as previously described. Previous in vitro studies have demonstrated that the hemolytic activities of alkoxyacetic acids with straight alkyl chains increased as the length of the alkyl chain extended to a maximum of 4 carbons (butoxyacetic acid), but declined when the chain length increased to 5 carbons (pentoxyacetic acid), and that propoxyacetic acid and pentoxyacetic acids have similar hemolytic potency (Ghanayem et al., 1989). These results suggest that EGHE may have lower hemolytic effects than EGPE in vivo. EGHE did not reveal any hemolytic effects under relatively lower inhaled exposure conditions (Klonne et al., 1987).

Diethylene glycol butyl ether (DGBE) has an EGBE substructure on its molecule. Oxidative degradation of DGBE may result in the formation of EGBE. However, a previous metabolism study has demonstrated that the terminal alcohol moiety of DGBE is oxidized to generate butoxyethoxyacetic acid as a major metabolite; and butoxyacetic acid was not detectable (Fig. 2D) (Deisinger and Guest, 1989). Hence DGBE was concluded not to be in this category. Repeated administration of DGBE for 13 weeks showed very slight hemolytic anemia in rats at 7.6 $\mathrm{mmol} / \mathrm{kg} / \mathrm{d}$ (Johnson et al., 2005).

PGME undergoes a conjugation reaction with glucuronide and sulfate, and $O$-dealkylation (Miller et al., 1984a); methoxyacetic acid is not formed (Fig. 2E), suggesting no hemolytic effects of PGME as PGMEA. One study confirms that repeated administration of PGME induces no hemolytic effects (Landry et al., 1983). It is reasonable to presume that methylation of the alpha carbon of EGPE affords a protective effect against hemolysis, probably by changing the metabolic pathway such that no methoxyacetic acid is formed. The metabolism feature and nonhemolytic effects are predicted to be similar in PGPE and PGBE, which can be confirmed by a series of RDT studies of these chemicals (ECETOC, 1995).

Evaluating the proposed category with seven chemicals clearly demonstrated the validity of this category for hemolytic effects of EGAEs and related chemicals. Given all structural information on category chemicals in Tables 2 and 3, the category can be finally defined as EGAEs (alkyl chain carbon number: 1-4) and their acetates. 
Category approach for repeated-dose toxicity

Table 3. A toxicity data matrix for EGAEs and related chemicals from the RepDose DB for evaluating a category

\begin{tabular}{lccc}
\hline & Alkoxyacetic acid & Hemolytic effects & Hemolytic effects and levels ${ }^{*_{1}}$ \\
Chemical structure & formation & in silico & Strain of rat, duration, route \\
Name & (in vitro) & (predicted hemolytic & Dose \\
CAS No. & (in vilico) & levels) & \\
\hline
\end{tabular}<smiles>CCCOCCO</smiles>

EGPE 2807-30-9<smiles>CCCOCCOC(C)=O</smiles>

EGPEA 20706-25-6

$\begin{array}{cc}+ & \text { (Levels between } \\ \text { (in silico }) & \text { EGEE and EGBE) }\end{array}$

(in silico)

(Similar levels to EGPE)

$\mathrm{LOAEL}_{\mathrm{RBC} \downarrow} ; 1.9 \mathrm{mmol} / \mathrm{kg} / \mathrm{d}$

SD rat, 6-w, gavage

$1.88,3.75,7.5,15 \mathrm{mmol} / \mathrm{kg} / \mathrm{d}$
$\mathrm{LOAEL}_{\mathrm{RBC} \downarrow} ; 7.5 \mathrm{mmol} / \mathrm{kg} / \mathrm{d}$

SD rat, 6-w, gavage $7.5,15,30 \mathrm{mmol} / \mathrm{kg} / \mathrm{d}$
No effects on RBC; $71 \mathrm{ppm}(0.67 \mathrm{mmol} / \mathrm{kg} / \mathrm{d})$

F344 rat, 13-w, 5 d/w, inhalation 20, 41, $71 \mathrm{ppm}$

(in silico)

(Levels less than EGPE)

$112-25-4$

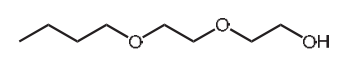

DGBE

112-34-5<smiles>COCC(C)O</smiles>

PGME

107-98-2

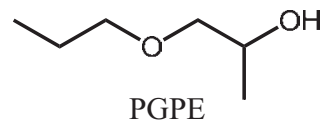

1569-01-3

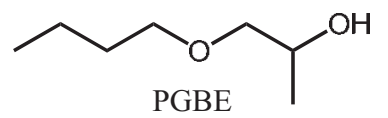

(in silico)
$\mathrm{LOAEL}_{\mathrm{RBC}} ; 1000 \mathrm{mg} / \mathrm{kg} / \mathrm{d}(6.2 \mathrm{mmol} / \mathrm{kg} / \mathrm{d})$

F344 rat, 13-w, drinking water $50,250,1000 \mathrm{mg} / \mathrm{kg} / \mathrm{d}$

No effects on RBC; $3000 \mathrm{ppm}(28 \mathrm{mmol} / \mathrm{kg} / \mathrm{d})$

F344 rat, 13-w, inhalation 300, 1000, $3000 \mathrm{ppm}$

No effects on RBC; 300 ppm $(2.8 \mathrm{mmol} / \mathrm{kg} / \mathrm{d})$

F344 and SD rat, 98-d, inhalation 30, 100, $300 \mathrm{ppm}$

5131-66-8

${ }^{*}{ }_{1}$ Hemolytic level was presented as $\mathrm{LOAEL}_{\mathrm{RBC} \downarrow}$. $\mathrm{BMDL}_{10 \mathrm{RBC} \downarrow}$ was not shown because the standard deviation and number of animals used are not given in most of the RDT reports. ${ }^{*}$ Strain could not be identified.

\section{Prediction of hemolytic effects of EGAEs and related chemicals without available RDT data}

As a trial of the category approach, prediction of hemolytic effects was tested for the following four chemicals without available RDT data: ethylene glycol isopropyl ether acetate (EGiPEA), ethylene glycol isobutyl ether (EGiBE), ethylene glycol butyl ether acetate (EGBEA) and diethylene glycol propyl ether (DGPE) (Table 4). No documented metabolism information was found for EGiPEA or EGBEA. By analogy to the observed metabolism of EGEEA and DGBEA and predicted metabolism of EGPEA in Fig. 2B, EGiPEA and EGBEA are expected to be almost completely susceptible to metabolic hydrolysis. It is thus reasonable to predict that EGiPEA and EGBEA would be included in the category, and that the presumed NOAEL of hemolysis would be similar to those 
(A)

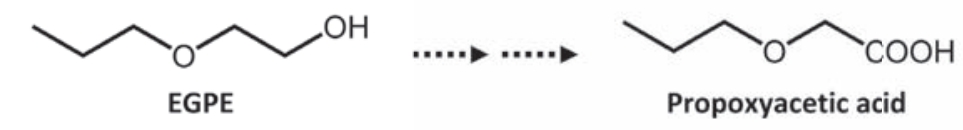

(B)

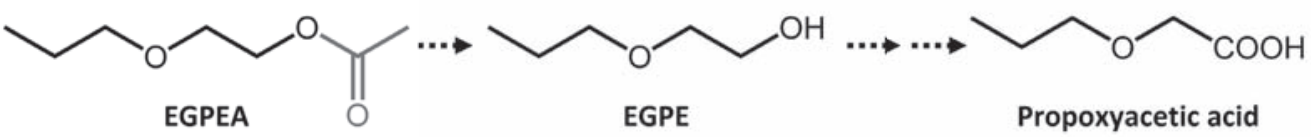

(C)

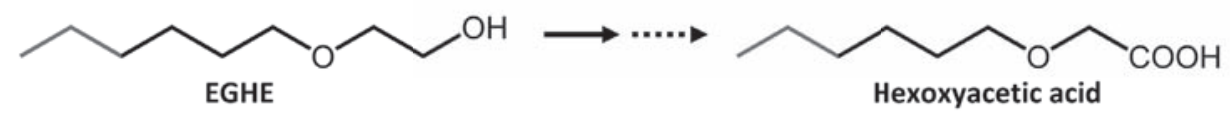

(D)

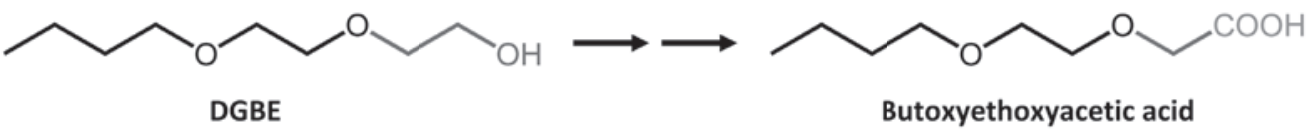

(E)

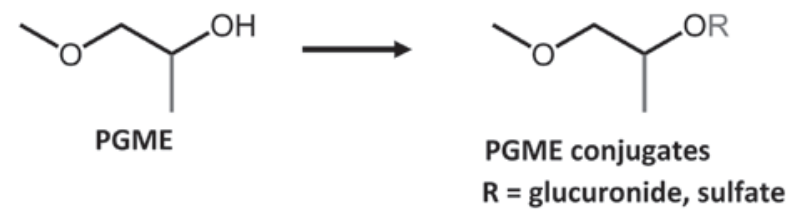

and<smiles>CC(O)CO</smiles>

Propylene glycol

Fig. 2. Documented and predicted major metabolic pathways in rats of EGAEs and related chemicals from RepDose DB. EGAE substructures with 3 or 4 alkyl carbons and the other moieties are shown in black and gray, respectively. Solid and dotted arrows respectively represent observed and predicted metabolic reactions. See the Results section for a detailed description.

of the corresponding EGAEs with $\mathrm{BMDL}_{10 \mathrm{RBC} \downarrow}$ of 0.74 and $0.86 \mathrm{mmol} / \mathrm{kg} / \mathrm{d}$, respectively. EGiBE has no empiric metabolism data, but it can be predicted to form the corresponding alkoxyacetic acid in the same way as the other category members. It is less likely that the hemolytic level of EGiBE would be different from those of EGPE, EGiPE, EGtBE or EGBE, since molecular size, hydrophobicity and reactivity are apparently similar among the five chemicals, and the alkoxyacetic acid moiety is critical for hemolytic activity. EGAEs with branched alkyl chains of 3 and 4 carbons (EGiPE and EGtBE, respectively) appear to be slightly more hemolytic than those with straight alkyl chains (EGPE and EGBE). Moreover, EGtBE is more hemolytic than EGiPE. The presumed NOAEL of hemolysis of EGiBE can be roughly estimated to be similar to BMDL $\mathrm{BMRC}_{10 \mathrm{RBC}}$ of $\operatorname{EGtBE}(0.33 \mathrm{mmol} / \mathrm{kg} / \mathrm{d})$ on the protective side. DGPE is presumed not to be a category member, since it does not seem to yield hemolytic alkoxyacetic acids via metabolism like DGBE.

\section{DISCUSSION}

New chemical management programs such as the Registration, Evaluation and Authorization of CHemicals $(\mathrm{REACH})$ in the European Union require hazard evaluation for many marketed chemicals and also call for minimizing animal testing. Therefore, several initiatives have emerged to adopt alternative methods for hazard evaluation. A mechanistic interpretation is necessary for regulatory acceptance of toxicity prediction using an alternative strategy. Herein we have attempted to develop and evaluate a mechanism-based category approach for hemolytic effects of EGAEs and related chemicals.

The data quality used in this study is reasonably high because all the data were derived from RDT DB and RepDose DB, where studies were carefully selected by data quality (Hayashi and Sakuratani, 2011; Bitsch et al., 2006). The toxicity endpoint of the category is hemolytic effects, which is one of the endpoints used for regulatory decisions. It can be clearly identified by hematology data, including significant decrease in RBC counts, hemoglobin concentration and hematocrit, accompanied by signif- 
Category approach for repeated-dose toxicity

Table 4. A data matrix for prediction of hemolytic effects of untested EGAEs and related chemicals

Chemical structure

Name

CAS No.
Alkoxyacetic acid formation $(\text { in silico })^{* 1}$
Hemolytic effects in silico

(Predicted hemolytic levels)<smiles>CC(=O)C(C)C(C)C(C)C</smiles>

19234-20-9

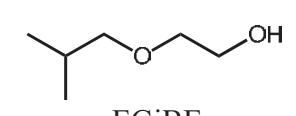

EGiBE

(Similar levels to EGBE)

${ }^{*}{ }^{1}$ Metabolism was presumed in silico by considering documented metabolism information of structurally related chemicals. See the Results section for a detailed description.

icant increase in reticulocyte counts and splenic hemosiderin pigmentation in RDT test reports.

EGAEs are hemolytic. Certain EGAE analogs are also hemolytic, but some are not (Tables 2 and 3). The current RDT test data can be interpreted in the light of the evidence that alkoxyacetic acid, a major metabolite of EGAEs, is toxic to RBCs and that hemolytic EGAE analogs appear to be metabolized to alkoxyacetic acid (Ghanayem et al., 1987; Ghanayem, 1989; Ghanayem et al., 1989; Udden and Patton, 2005; Starek et al., 2008). Previous in vitro studies have demonstrated no hemolytic activity for heptanoic acid, which has a similar chain length but no ether oxygen, or propoxypropionic acid which is isomeric with butoxyacetic acid but has the ether linkage in a different position (Ghanayem et al., 1989). The results strongly indicate that the hemolytic effects might be started by a specific interaction between the alkoxyacetic acid moiety and an unidentified RBC component. The theoretical severity of EGAE-induced hemolytic effects in vivo can be influenced by the hemolytic activities of alkoxyacetic acids as well as toxicokinetic factors including the concentrations of alkoxyacetic acids in the blood during repeated administration. The ranking order of hemolytic activity in vitro was butoxyacetic acid $>$ propoxyacetic acid $>$ ethoxyacetic acid $>$ methoxyacetic acid (Ghanayem et al., 1989). Urinary alkoxyacetic acids in rats constituted 50 to $60 \%$ of the dose for EGBE, $25 \%$ to $40 \%$ for EGEE and $34 \%$ for EGME $72 \mathrm{hr}$ post administration (Medinsky et al., 1990). Hence, the carbon number of straight alkyl chains (up to 4) of EGAEs appears to correlate with both hemolytic activity and metabolic formation of alkoxyacetic acids as well as intensity of hemolytic effects. EGAE isomers with branched alkyl chains containing 3 and 4 carbons appear to be slightly more hemolytic than straight-chain versions. Furthermore, EGAE isomers with 4 alkyl carbons appear to be more hemolytic than those with 3 alkyl carbons, although there were variations in the administration period during testing (Table 2).

Given all structural information on category chemicals identified in RDT DB and RepDose DB, the category can be finally defined as a group of EGAEs (alkyl chain carbon number: 1-4) and their acetates (Tables 2 and 3). The applicability domain is described by alkyl chain car- 
Table 5. Summary of structure-toxicity relationship of EGAEs and their acetate in RDT

\begin{tabular}{lcl}
\hline Chemical & Alkyl carbon No. Critical toxic effects \\
\hline EGME & 1 & Testicular degeneration/atrophy \\
EGEE & 2 & Testicular degeneration/atrophy \\
EGPE & 3 & Hemolysis \\
EGPEA & 3 & Hemolysis \\
EGiPE & 3 & Hemolysis \\
EGBE & 4 & Hemolysis \\
EGtBE & 4 & Hemolysis \\
EGHE & 6 & Hepatocyte hypertrophy \\
\hline
\end{tabular}

bon number in the EGAE molecule, since the alkyl carbon number acts as a structural cutoff within the category chemicals. Acetates of EGAE are within the category, since available evidence demonstrates that EGAE acetates are readily hydrolyzed to EGAE counterparts, and that EGAE and their acetates appear to exhibit similar metabolic fate. There is no available metabolic and toxicological data for other fatty acid esters of EGAE. However, the difference in saturated alkyl chain should not have significant impact on chemical reactivity and metabolic hydrolysis (Wu et al., 2010). Hence, series of EGAE esters with different straight saturated fatty chain may yield hemolytic effects via similar metabolic pathway. It should be noted that chemicals often have multiple toxic endpoints in RDT. Both EGME and EGEE are hemolytic, but primarily cause toxic effects in testis at a lower dose where hemolysis is not yet evident (NTP, 1993) (Table 5). Therefore, testicular toxicity needs to be considered rather than hemolytic effects for untested category members with 1 and 2 alkyl chain carbon(s) to be able to estimate the presumed NOAEL for RDT. An in vitro structure-toxicity relationship study demonstrated that pentoxyacetic acid (5 carbons) was hemolytic in rat RBCs at about half the potency of butoxyacetic acid (Ghanayem et al., 1989). EGHE was not hemolytic, but the maximum dose was relatively lower in one study (Klonne et al., 1987). Hence, it is possible that EGHE is still hemolytic at higher doses, and the applicability domain might be expanded to 6 alkyl carbons if the hemolytic effects appear at higher doses. However, EGHE appears to be hepatotoxic at doses below which hemolysis is not yet evident (Klonne et al., 1987) (Table 5). Taken together, the category approach in this study can be practically applied to EGAEs with alkyl chain carbon numbers 3 and 4 and their acetates to estimate presumed NOAEL for RDT (Table 5).
A critical step for applying the category approach is to categorize chemicals with a common toxic mechanism. However, untested chemicals often lack mechanistic information: the only available information is chemical structure and physicochemical properties. It is thus necessary to measure or predict whether untested chemicals cause key events linked to an adverse outcome. In the proposed category, metabolic formation of hemolytic alkoxyacetic acids is a measurable or predictable key event associated with hemolytic effects. Fig. 3 illustrates the scheme of category approach for hemolytic effects of EGAEs. Untested category candidates are primarily screened based on the EGAE substructure with alkyl chain carbon numbers of 3 and 4 as well as similar physicochemical properties and chemical reactivity. This step can be supported by computer software equipped with function to search structural analogs with toxicity data, such as Hazard Evaluation Support System (HESS) which we will release soon or OECD QSAR Toolbox (Hayashi and Sakuratani, 2011). The target chemicals are then determined as to whether they are category members by considering hemolytic alkoxyacetic acid formation using documented metabolism data on structural analogs in the metabolism database. Finally the hemolytic levels are estimated by read-across using toxicity data for category chemicals (e.g., BMDL $\mathrm{BMR}_{10 \mathrm{RBC} \downarrow}$ or $\mathrm{LOAEL}_{\mathrm{RBC} \downarrow}$ ). Expertise is necessary for interpreting available data and making decision. Results of category validation support the reliability of prediction of hemolytic effects of untested EGAE and their acetates.

Finally, mechanism-based category approach is potentially useful to extrapolate hazard evaluation in experimental animals to human. Results from in vitro experiments indicated that rat RBCs are more susceptible than human ones to hemolytic effects to butoxyacetic acid with variation from about 3 to 100-fold (Udden, 2002; Starek et al., 2008). On the other hand, case reports of humans intoxicated by injesting EGBE suggested that it causes severe toxicity including hemolytic anemia (Gijsenbergh et al., 1989; Rambourg-Schepens et al., 1988). Moreover, differences in the susceptibility and toxicokinetic feature between rat and human have not been fully characterized for other hemolytic alkoxyacetic acids. Hence, more detailed information is needed for mechanism-based extrapolation. If the hemolytic effects prove less relevant to human, this information should be considered for risk assessment to human exposed to the category chemicals.

In summary, we have explored a category approach for hemolytic effects of EGAEs and their acetates in RDT. We conclude that our developed category approach model has potential for regulatory-acceptable prediction of the 
Category approach for repeated-dose toxicity

$\begin{array}{lll}\begin{array}{c}\text { Structure-based } \\ \text { screening of }\end{array} & \begin{array}{c}\text { Mechanism-based } \\ \text { categorization of }\end{array} & \text { Toxicity prediction } \\ \underline{\text { untested chemical }} & \underline{ }\end{array}$

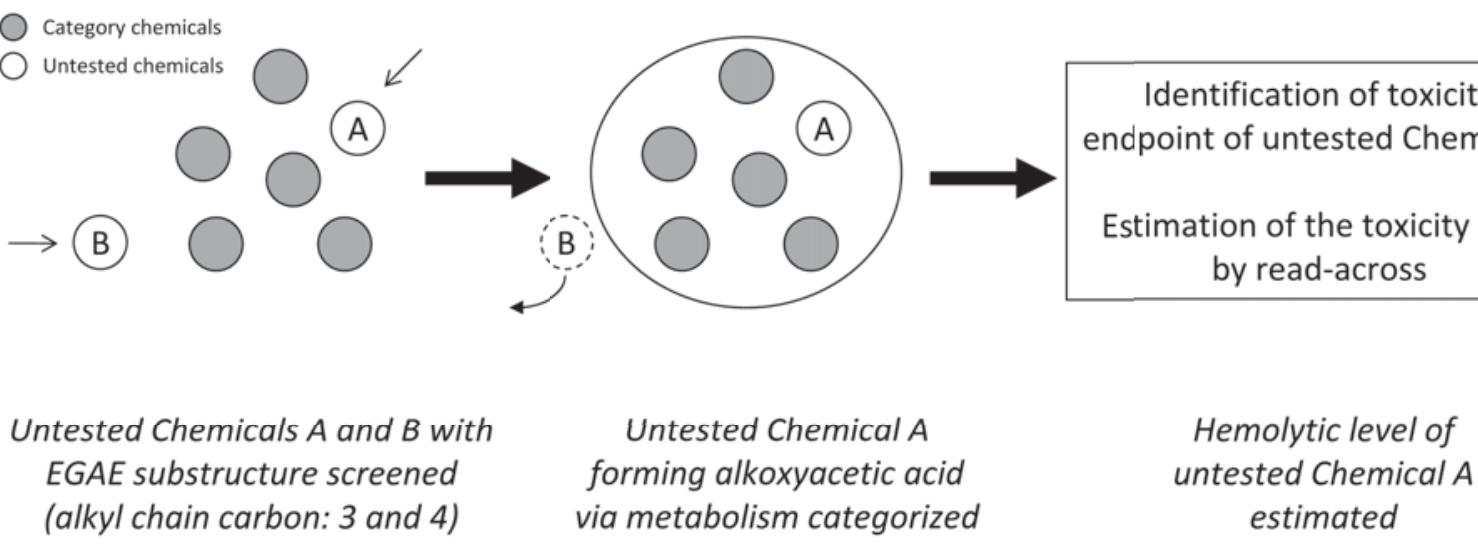

Fig. 3. Scheme of mechanism-based category approach for EGAEs and related chemicals to predict hemolytic effects. Untested category candidates are primarily screened based on the EGAE (sub)structure with alkyl chains with 3 and 4 carbons (untested Chemicals A and B) and similarity of the physicochemical properties and chemical reactivity. The substances are determined as to whether they are category members based on the generation of hemolytic alkoxyacetic acid. Untested Chemical A is included in the category if the alkoxyacetic acid is formed, and untested Chemical B is removed if it is not. Finally, the hemolytic level of untested Chemical A is estimated by read-across using existing toxicity data on category chemicals.

hemolytic effects of the untested analogs.

\section{ACKNOWLEDGMENTS}

This work was supported by grants from the New Energy and Industrial Technology Development Organization (NEDO) (2007-2010) and the Ministry of Economy, Trade and Industry (METI) (2011) for the "Development of Hazard Assessment Techniques Using Structure-activity Relationship Methods."

\section{REFERENCES}

Aasmoe, L., Winberg, J.O. and Aarbakke, J. (1998): The role of liver alcohol dehydrogenase isoenzymes in the oxidation of glycolethers in male and female rats. Toxicol. Appl. Pharmacol., 150, 86-90.

Ankley, G.T., Bennett, R.S., Erickson, R.J., Hoff, D.J., Hornung, M.W., Johnson, R.D., Mount, D.R., Nichols, J.W., Russom, C.L., Schmieder, P.K., Serrano, J.A., Tietge, J.E. and Villeneuve, D.L. (2010): Adverse outcome pathways: a conceptual framework to support ecotoxicology research and risk assessment. Environ. Toxicol. Chem., 29, 730-741. Review.

Bitsch, A., Jacobi, S., Melber, C., Wahnschaffe, U., Simetska, N. and Mangelsdorf, I. (2006): REPDOSE: A database on repeated dose toxicity studies of commercial chemicals - A multifunctional tool. Regul. Toxicol. Pharmacol., 46, 202-210.

Blackburn, K., Bjerke, D., Daston, G., Felter, S., Mahony, C.,
Naciff, J., Robison, S. and Wu, S. (2011): Case studies to test: A framework for using structural, reactivity, metabolic and physicochemical similarity to evaluate the suitability of analogs for SAR-based toxicological assessments. Regul. Toxicol. Pharmacol., 60, 120-35.

Cheever, K.L., Plotnick, H.B., Richards, D.E. and Weigel, W.W. (1984): Metabolism and excretion of 2-ethoxyethanol in the adult male rat. Environ. Health Perspect., 57, 241-248.

Concise International Chemical Assessment Document 67 (CICAD) (2005): Selected alkoxyethanols 2-butoxyeethanol. World Health Orgaization.

Deisinger, P.J. and Guest, D. (1989): Metabolic studies with diethylene glycol monobutyl ether acetate (DGBA) in the rat. Xenobiotica, 19, 981-989.

Domoradzki, J.Y., Brzak, K.A. and Thornton, C.M. (2003): Hydrolysis kinetics of propylene glycol monomethyl ether acetate in rats in vivo and in rat and human tissues in vitro. Toxicol. Sci., 75, 31-39.

ECETOC Technical Report No. 95 (1995): The toxicology of glycol ethers and its relevance to man (Fourth Edition) volume II - substance profiles. European Centre for Ecotoxicology and Toxicology of Chemicals.

Fabjan, E., Hulzebos, E., Mennes, W. and Piersma, A.H. (2006): A category approach for reproductive effects of phthalates. Crit. Rev. Toxicol., 36, 695-726.

Gargas, M.L., Tyler, T.R., Sweeney, L.M., Corley, R.A., Weitz, K.K., Mast, T.J., Paustenbach, D.J. and Hays, S.M. (2000): A toxicokinetic study of inhaled ethylene glycol ethyl ether acetate and validation of a physiologically based pharmacokinetic model for rat and human. Toxicol. Appl. Pharmacol., 165, 63-73. 
Ghanayem, B.I., Burka, L.T. and Matthews, H.B. (1987): Metabolic basis of ethylene glycol monobutyl ether (2-butoxyethanol) toxicity: role of alcohol and aldehyde dehydrogenases. J. Pharmacol. Exp. Ther., 242, 222-231.

Ghanayem, B.I. (1989): Metabolic and cellular basis of 2-butoxyethanol-induced hemolytic anemia in rats and assessment of human risk in vitro. Biochem. Pharmacol., 38, 1679-1684.

Ghanayem, B.I., Burka, L.T. and Matthews, H.B. (1989): Structureactivity relationships for the in vitro hematotoxicity of N-alkoxyacetic acids, the toxic metabolites of glycol ethers. Chem. Biol. Interact., 70, 339-352.

Gijsenbergh, F.P., Jenco, M., Veulemans, H., Groeseneken, D., Verberckmoes, R. and Delooz, H.H. (1989): Acute butylglycol intoxication: a case report. Hum. Toxicol., 8, 243-245.

Hayashi, M. and Sakuratani, Y. (2011): Development of an evaluation support system for estimating repeated-dose toxicity of chemicals based on chemical structure. In New Horizons in Predictive Toxicology: Current Status and Application (Rsc Drug Discovery) (Wilson, A.G.E., ed.), Chap. 3, Royal Society of Chemistry, Cambridge.

Hutson, D.H. and Pickering, B.A. (1971): The metabolism of isopropyl oxitol in rat and dog. Xenobiotica, 1, 105-119.

Johanson, G. (2000): Toxicity review of ethylene glycol monomethyl ether and its acetate ester. Crit. Rev. Toxicol., 30, 307-345.

Johnson, W.Jr. (2002): Cosmetic Ingredient Review Expert panel. Final report on the safety assessment of ethoxyethanol and ethoxyethanol acetate. Int. J. Toxicol., 21, 9-62.

Johnson, K.A., Baker, P.C., Kan, H.L., Maurissen, J.P., Spencer, P.J. and Marty, M.S. (2005): Diethylene glycol monobutyl ether (DGBE): two- and thirteen-week oral toxicity studies in Fischer 344 rats. Food Chem. Toxicol., 43, 467-481.

Katz, G.V., Krasavage, W.J. and Terhaar, C.J. (1984): Comparative acute and subchronic toxicity of ethylene glycol monopropyl ether and ethylene glycol monopropyl ether acetate. Environ. Health Perspect., 57, 165-175.

Klonne, D.R., Dodd, D.E., Pritts, I.M., Troup, C.M., Nachreiner, D.J. and Ballantyne, B. (1987): Acute, 9-day, and 13-week vapor inhalation studies on ethylene glycol monohexyl ether. Fundam. Appl. Toxicol., 8, 198-206.

Landry, T.D., Gushow, T.S. and Yano, B.L. (1983): Propylene glycol monomethyl ether: a 13-week inhalation toxicity study in rats and rabbits. Fundam. Appl. Toxicol., 3, 627-630.

Medinsky, M.A., Singh, G., Bechtold, W.E., Bond, J.A., Sabourin, P.J., Birnbaum, L.S. and Henderson, R.F. (1990): Disposition of three glycol ethers administered in drinking water to male F344/N rats. Toxicol. Appl. Pharmacol., 102, 443-455.

Miller, R.R., Hermann, E.A., Young, J.T., Landry, T.D. and Calhoun, L.L. (1984a): Ethylene glycol monomethyl ether and propylene glycol monomethyl ether: metabolism, disposition, and subchronic inhalation toxicity studies. Environ. Health Perspect., 57, 233-239.

Miller, R.R., Hermann, E.A., Young, J.T., Calhoun, L.L. and Kastl P.E. (1984b): Propylene glycol monomethyl ether acetate (PGMEA) metabolism, disposition, and short-term vapor inhalation toxicity studies. Toxicol. Appl. Pharmacol., 75, 521-530.

Ministry of Health, Labor and Welfare (MHLW) (1998): Combined repeat dose and reproductive/developmental toxicity screening test of propylene glycol monomethyl ether acetate by oral administration in rats. http://dra4.nihs.go.jp/mhlw_data/home/ paper/paper108-65-6d.html

Ministry of Health, Labor and Welfare (MHLW) (2001): Combined repeat dose and reproductive/developmental toxicity screening test of 2-tert-butoxyethanol by oral administration in rats. http:// dra4.nihs.go.jp/mhlw data/home/paper/paper7580-85-0d.html

Ministry of Health, Labor and Welfare (MHLW) (2002): Twentyeight-day repeat dose oral toxicity test of 2-(1-methylethoxy) ethanol in rats. http://dra4.nihs.go.jp/mhlw_data/home/paper/ paper109-59-1b.html

National institute for occupational safety and health (NIOSH) (1990): Criteria for a recommended standard. Occupational exposure to ethylene glycol monobutyl ether and ethylene glycol monobutyl ether acetate. Cincinnati, $\mathrm{OH}$.

National Institute for Occupational Safety and Health (NIOSH) (1991): Criteria for a recommended standard. Occupational exposure to ethylene glycol monomethyl ether, ethylene glycol monoethyl ether, and their acetates. Cincinnati, $\mathrm{OH}$.

National Toxicology Program (NTP) (1993): NTP technical report on toxicity studies of ethylene glycol ethers (2-methoxyethanol, 2-ethoxyethanol and 2-butoxyethanol) administered in drinking water to F344/N rats and B6C3F1 mice. National Toxicology Program, Toxicity Report Series No. 26. NIH Publication 93-3349, July 1993, US DHHS, Public Health Services, National Institute of Health.

National Toxicology Program (NTP) (2000): Toxicology and carcinogenesis studies of 2-butoxyethanol (CAS No. 111-76-2) in F344/N rats and B6C3F1 mice (inhalation studies). Technical Report Series 484 (NIH Publication No. 00-3974).

Organisation for Economic Co-operation and Development (OECD). (2004): OECD SIDS initial assessment report for SIAM 19, Monomethylene glycol ethers category.

Organisation for Economic Co-operation and Development (OECD), (2007): Guidance of grouping chemicals. Series on Testing and Assessment No. 80.

Organisation for Economic Co-operation and Development (OECD). (2011): Report of the Workshop on Using Mechanistic Information in Forming Chemical Categories. Series on Testing and Assessment No. 138.

Rambourg-Schepens, M.O., Buffet, M., Bertault, R., Jaussaud, M., Journe, B., Fay, R. and Lamiable, D. (1988): Severe ethylene glycol butyl ether poisoning. Kinetics and metabolic pattern. Hum. Toxicol., 7, 187-189.

Sabourin, P.J., Medinsky, M.A., Thurmond, F., Birnbaum, L.S. and Henderson, R.F. (1992): Effect of dose on the disposition of methoxyethanol, ethoxyethanol, and butoxyethanol administered dermally to male F344/N rats. Fundam. Appl. Toxicol., 19, 124132.

Sakuratani, Y., Sato, S., Nishikawa, S., Yamada, J., Maekawa, A., and Hayashi, M. (2008): Category analysis of the substituted anilines studied in a 28-day repeat-dose toxicity test conducted on rats: correlation between toxicity and chemical structure. SAR QSAR Environ. Res., 19, 681-696.

Schaafsma, G., Kroese, E.D., Tielemans, E.L., Van de Sandt, J.J. and Van Leeuwen C.J. (2009): REACH, non-testing approaches and the urgent need for a change in mind set. Regul. Toxicol. Pharmacol., 53, 70-80.

Schultz, T.W. (2010): Adverse outcome pathways: a way of linking chemical structure to in vivo toxicological hazards. In In Silico Toxicology Principles and Applications (Cronin, M.T.D. and Madden, J.C. eds.), pp.351-376, The Royal Society of Chemistry, Cambridge.

Starek, A., Szabla, J., Kieć-Kononowicz, K. and Szymczak, W. (2008): Comparison of the in vitro hemolytic effects produced by alkoxyacetic acids on human and rat erythrocytes. Int. J. Occup. Med. Environ. Health., 21, 147-155. 
Category approach for repeated-dose toxicity

Stott, W.T. and McKenna, M.J. (1985): Hydrolysis of several glycol ether acetates and acrylate esters by nasal mucosal carboxylesterase in vitro. Fundam. Appl. Toxicol., 5, 399-404.

Sumner, S.J., Stedman, D.B., Cheng, S.Y., Welsch, F. and Fennell, T.R. (1995): Dose effects on the excretion of urinary metabolites of $2-\left[1,2\right.$, methoxy- $\left.{ }^{13} \mathrm{C}\right]$ methoxyethanol in rats and mice. Toxicol. Appl. Pharmacol., 134, 139-147.

Udden, M.M. (2000): Rat erythrocyte morphological changes after gavage dosing with 2-butoxyethanol: a comparison with the in vitro effects of butoxyacetic acid on rat and human erythrocytes. J. Appl. Toxicol., 20, 381-387.

Udden, M.M. (2002): In vitro sub-hemolytic effects of butoxyacetic acid on human and rat erythrocytes. Toxicol. Sci., 69, 258-264.

Udden, M.M. and Patton, C.S. (2005): Butoxyacetic acid-induced hemolysis of rat red blood cells: effect of external osmolarity and cations. Toxicol. Lett., 156, 81-93.

van Leeuwen, K., Schultz, T.W., Henry, T., Diderich, B. and Veith, G.D. (2009): Using chemical categories to fill data gaps in hazard assessment. SAR QSAR Environ. Res., 20, 207-220.

Wu, S., Blackburn, K., Amburgey, J., Jaworska, J. and Federle, T. (2010): A framework for using structural, reactivity, metabolic and physicochemical similarity to evaluate the suitability of analogs for SAR-based toxicological assessments. Regul. Toxicol. Pharmacol., 56, 67-81. 